\title{
A estrutura do parágrafo na compreensão leitora: um estudo exploratório
}

Paragraph structure in reading comprehension: an exploratory study

\section{José Ferrari Neto}

Universidade Federal da Paraíba - UFPB - João Pessoa - Paraíba - Brasil

\begin{abstract}
Resumo: $O$ presente trabalho investiga o papel da estrutura do parágrafo no processo de compreensão leitora. A leitura de um texto é um processo integrativo, no qual as informações processadas em um nível inferior vão sendo progressivamente integradas às informações processadas no nível posterior (KINTSCH; RAWSON, 2013). A compreensão de um nível é requerida para que a compreensão do nível subsequente ocorra. Os níveis se organizam em unidades textuais, que vão da palavra ao texto como um todo, passando pelo parágrafo. No estudo sobre a compreensão de textos é necessário, portanto, que se determine como as informações de um nível são extraídas, bem como são integradas ao nível seguinte, durante o processamento das unidades textuais. A questão de pesquisa aqui endereçada é, assim, a de se saber de que forma a organização do parágrafo, assumido aqui como uma unidade textual, afeta a compreensão global do texto (KINTSCH; VAN DIJK, 1978). Por outro lado, diferenças individuais também afetam o processamento e a compreensão do texto, na medida em que leitores sejam capazes de reconhecer a estrutura subjacente ao texto e às unidades textuais, usando-a como estratégia para extração de informações. Assim, outra questão de pesquisa é saber de que forma diferentes perfis de leitores reagem ao modo de estruturação do texto e de suas unidades (KIERAS, 1978). O presente trabalho teve como objetivos avaliar o papel da estruturação do parágrafo na compreensão leitora, identificar diferentes perfis leitores e como eles reagem diante da (boa/má) organização textual. Por meio de um experimento de leitura automonitorada (selfpaced reading), procurou-se categorizar os sujeitos, de modo a extrair os diferentes perfis leitores. Os resultados apontam para um papel decisivo da estrutura textual no processamento, estando a habilidade em processar essa estrutura diretamente ligada às habilidades individuais dos leitores.
\end{abstract}

Palavras-chave: Leitura, processamento, compreensão leitora.

Abstract: This paper investigates the role of paragraph structure in the reading comprehension process. Reading a text is an integrative process, in which information processed at a lower level is progressively integrated with information processed at a later level (KINTSCH; RAWSON, 2013). Understanding of a level is required for understanding of the subsequent level to occur. The levels are organized into textual units, ranging from the sentence to the whole text, including the paragraph. In the study of text comprehension, therefore, it is necessary to determine how information from one level is extracted, as well as how it is integrated to the next level, during the processing of textual units. Thus, The research question addressed here is how the paragraph arrangement, assumed here as a textual unit, affects the overall comprehension of the text (KINTSCH; VAN DIJK, 1978). On the other hand, individual differences also affect both text processing and comprehension, since readers are able to recognize the underlying structure of the text and the textual units, using them as a strategy for extracting information. Therefore, another research question is how different reader profiles deals with the way of the text and and its units are organized (KIERAS, 1978). The present work aimed to evaluate the role of paragraph structuring in reading comprehension, identify different reader profiles and how they deal with (good / bad) textual organization. By using a self-paced reading experiment, we sought to categorize the subjects in order to extract the different reader profiles. The results point to a decisive role of the textual structure in processing, being the ability to process this structure directly linked to the individual skills of the readers.

Keywords: Reading, processing, reading comprehension. 


\section{Introdução}

Pode-se definir o processamento linguístico em nível textual como o conjunto de operações mentais e cognitivas que subjazem ao processo de reconhecimento e extração de informações de um texto. Kintsch (1978) assinalou que esse processamento ocorre em diferentes níveis. Em linhas gerais, esses níveis podem ser caracterizados e descritos como sendo mais baixos (lowest levels), correspondentes ao que Kintsch e Rawson (2013) denominaram nível linguístico, o qual é concernente ao reconhecimento das relações entre grafemas e fonemas, reconhecimento das palavras e seus significados básicos, constituindo assim o nível da decodificação da língua escrita por meio da leitura. Além desse, Kintsch e Rawson (2013) apontaram também para a existência dos níveis intermediários (intermediate levels), os quais são relativos à identificação das relações entre as palavras na sentença e entre as sentenças entre si, o que torna possível reconhecer a estrutura semântica $e$ informacional básica, sendo, por essa razão, denominados nível semântico. Por fim, os autores propuseram o processamento em níveis mais altos (highest levels), os quais são referentes à construção mental da macro-estrutura textual, e dos frames, esquemas e gêneros textuais que sustentam o que eles chamaram de base textual, que representa 0 significado global do texto.

Durante a leitura, as informações identificadas são processadas de modo a proverem os dados necessários para que a compreensão requerida em seu respectivo nível ocorra de forma a mais plena possível. Uma vez alcançada essa etapa, a compreensão aí alcançada serve de base para a inicialização do processo no nível seguinte. O processo de leitura de um texto é, portanto, integrativo, no qual as informações processadas em um nível inferior vão sendo progressivamente integradas às informações processadas no nível posterior, com a compreensão de um nível sendo requerida para que a compreensão do nível subsequente ocorra. Para isso, é necessário que o texto esteja estruturado de forma a permitir tanto a identificação de informações em cada nível quanto a sua integração em sua totalidade. Dessa forma, ao se estudar os processos de leitura e compreensão de um texto, exige-se que a investigação seja feita enfocando-se os mecanismos de identificação e integração básicas, bem como os que atuam no nível da sua organização global. Para, então, empreender uma investigação acerca do grau de compreensão de um texto, bem como sobre os fatores que estão envolvidos nesse processo, é necessário em primeiro lugar determinar em que nível textual (ou em que níveis textuais) se dá o processamento e como as informações desse nível são reconhecidas e extraídas e, em segundo, como essas informações são integradas no nível seguinte, durante 0 seu processamento.

Neste trabalho, assume-se, como ponto de partida, o reconhecimento de informações semânticas contidas no nível das sentenças constituintes de um texto. Essas consubstanciam-se em unidades do nível intermediário, combinando-se entre si de forma a constituir a estrutura textual de superfície que engloba também a unidade textual do parágrafo, de cuja combinação vai resultar a estrutura textual profunda, já no nível macrotextual (KINTSCH; VAN DIJK, 1978). No que se refere à sua estrutura, aplicam-se ao parágrafo os mesmos fatores que se assumem como decisivos para a boa compreensão do texto - a saber, que seja organizado de forma a permitir tanto a identificação das informações quanto a sua integração em um nível mais acima. Sendo assim, pode-se especular que fatores que acarretem uma má estruturação do parágrafo podem conduzir a uma compreensão deficiente ou até mesmo errônea do texto. Uma investigação sobre os processos subjacentes de compreensão leitora que assumam o parágrafo como uma unidade composicional textual deve, por conseguinte, considerar se organização do parágrafo afeta a compreensão global do texto como uma questão a ser explorada. Com efeito, essa questão tem sido tratada, sob diferentes vieses, pelo menos desde os estudos seminais de Kintsch \& Van Dijk (1978) acerca de modelos de compreensão e produção de textos. 
De acordo com Kieras (1978), de um modo geral, e ao menos no que se refere ao texto expositivoargumentativo, a estrutura do parágrafo pode ser determinada pela topicalização inicial, a qual requer que o parágrafo se inicie com uma afirmação de um tema ou ideia principal, pela coerência textual, a qual exige que as sentenças apresentem uma estrutura proposicional e que estejam organizadas de modo a constituir uma harmonia entre as informações presentes no texto e seus referentes externos, e pela coesão textual, que impõe que cada sentença subsequente se ligue, formal e semanticamente, à sentença precedente, articulando as informações numa organização entre informação dada e informação nova. Assim, um texto bem estruturado, e do mesmo modo um parágrafo bem estruturado, é o que obedece, no mais alto grau possível, a esses fatores, tomados de modo integrado, e nunca isoladamente.

No que tange aos fatores que possibilitam que as informações sejam absorvidas pelo leitor durante o processo de leitura, garantindo assim que ele seja compreendido, pode-se assumir que uma boa compreensão do texto é produto tanto de sua adequada estruturação, medida em graus de obediência aos fatores acima apontados, quanto de seu processamento, o qual é concernente aos processos cognitivos de reconhecimento e decodificação de informações linguísticas. Assim, pode-se postular que, quanto mais bem estruturado um texto, conforme os fatores já elencados, melhor será o seu processamento e, consequentemente, a sua compreensão.

Ainda sob essa perspectiva, cumpre destacar que os processos de compreensão e processamento de textos são, em grande medida, afetados por características particulares de cada leitor, as quais envolvem níveis de competências distintos, fatores ligados ao conhecimento linguístico geral e ainda diferenças concernentes a recursos básicos requeridos pelas operações de processamento, como sistemas perceptuais, sistemas atencionais e capacidades de memória de trabalho. Diferenças individuais, possivelmente, afetam o processamento e a compreensão do texto, na medida em que leitores mais proficientes possam ser mais capazes de reconhecer a estrutura subjacente, usando-a como estratégia para extração de informações. Portanto, uma questão que surge da pesquisa sobre 0 processamento textual é a de se saber de que forma diferentes perfis de leitores reagem ao modo de estruturação do texto.

Essa questão foi desenvolvida, primeiramente, por Kieras (1978), em uma série de experimentos offline sobre leitura e compreensão de textos, mas tem sido retomada atualmente, sobretudo em trabalhos que têm investigado 0 papel das diferenças individuais no processamento da leitura de textos (HYÖNÄ; LORCH JR.; KAAKINEN, 2002) assim como os que têm buscado caracterizar as habilidades de compreensão em leitores maduros (LONG; JOHNS; MORRIS, 2006). Mesmo no nível da sentença, é possível apontar estudos que focaram o processo de identificação de informações constantes em orações em posições hierarquicamente distintas por parte de leitores de diferentes perfis, como foi o caso do estudo inicial de Maia (2018) sobre o processamento de períodos em português brasileiro (PB). Assim, o presente trabalho discorre precisamente sobre essas duas questões, no intuito principal de prover evidências empíricas iniciais acerca do processamento textual em PB, sobretudo no que tange ao papel da estruturação textual, especificamente, do parágrafo, no processo de identificação e compreensão de informações, e na caracterização do modo como os leitores reagem diante dessa estruturação durante a atividade de leitura. Assume-se como hipótese de trabalho a ideia de que a estruturação textual, definida como a organização e conexão dos conteúdos do texto em seus níveis e unidades constituintes, determina as estratégias possíveis a serem aplicadas pelos leitores no processo de compreensão do texto, uma vez que esses reagem diferentemente a padrões distintos de organização textual. Por meio da técnica experimental da leitura auto-monitorada (self-paced reading), buscou-se obter dados que permitissem não apenas investigar os fatores envolvidos na adequada estruturação do texto, mas também prover dados que, 
por meio do procedimento estatístico da análise de agrupamentos (cluster analysis), possibilitassem a identificação de diferentes perfis de leitores.

$\mathrm{O}$ artigo se organiza na seguinte forma. $\mathrm{Na}$ seção seguinte são apresentados e discutidos trabalhos prévios sobre o tema, cuja análise permite fundamentar os aspectos teóricos e metodológicos seguidos aqui. Em seguida, é descrito todo o procedimento experimental empregado, desde a formulação dos estímulos até a aplicação do experimento. Por fim, os resultados são mostrados e discutidos na última seção, com vistas à evidenciação das hipóteses aqui assumidas.

\section{A formação da estrutura textual durante o processamento}

A pesquisa sobre o processamento da leitura tem revelado os mecanismos subjacentes à construção online da estrutura textual por parte dos leitores. Em linhas gerais, os resultados têm mostrado que diversos fatores concorrem para que os leitores identifiquem a estrutura do texto. Dentre esses fatores, podem-se citar os concernentes à maneira como são formadas, em nível mental, as conexões entre proposições, seja de natureza (co)referencial, semântica, lógica ou inferencial (KINTSCH; RAWSON, 2013), assim como os relativos à percepção das relações dado-novo e de hierarquizações de informações (KIERAS, 1978). Tomados em conjunto, o estudo sobre 0 papel desses fatores no processamento tem focado no modo como é construída a base textual, durante a atividade de leitura.

No que toca ao estabelecimento de conexões entre as unidades textuais, notadamente, entre proposições e sentenças, a pesquisa tem revelado a importância dos conectivos nesse processo e o papel desses elementos na identificação das relações lógicas, semânticas e inferenciais, tanto em $\mathrm{PB}$ (SIMÕES, 2019) quanto em outras línguas (MILLIS; JUST,1994; TRAXLER et al, 1997; MURRAY, 1997; SAN- DERS; NOORDMAN, 2000; NOORDMAN; VONK, 2014; NOORDMAN et al, 2015). No que concerne às relações dado-novo e à hierarquização de informações, os estudos têm sido agrupados em torno da pesquisa sobre a formação da macroestrutura textual e reconhecimento de tópicos, mostrando que fatores como repetição de palavras (SURBER, 2001) e topicalização inicial de texto ou parágrafo (BUDD; WHITNEY; TURLEY, 1995) são tomados como pistas decisivas no processamento da estrutura do texto. Dessa forma, uma investigação sobre como a estrutura do texto, em especial a do parágrafo, pode afetar a compreensão deve, por suposto, considerar esses aspectos de algum modo.

O estudo aqui apresentado recai justamente sobre o segundo desses aspectos. Assume-se, conforme Kintsch e van Dijk (1978), que a compreensão de um texto é produto de uma série de operações mentais, dentre as quais aponta-se as que organizam os múltiplos elementos de texto em um todo coerente, daí resultando a constituição do texto como unidade temática e formal. Sendo assim, e ainda de acordo com Kintsch e van Dijk (1978), os textos não podem ser considerados como uma mera sequência de unidades não relacionadas, mas sim como uma estrutura coerente de unidades constituintes. Essa estrutura é hierárquica - em um texto, as ideias se organizam em torno de uma única ideia central, a qual confere unidade temática, com o entrelaçamento entre as demais, conferindo a devida coesão ao texto. No nível do parágrafo, pelo menos desde Kintsch (1974), é possível assumir que essa hierarquização é devida ao fato de haver uma superordenação de proposições, com a primeira de suas sentenças contendo a ideia principal, com as demais sentenças ligadas a ela de alguma forma. Tal estruturação conferiria um status cognitivo-perceptual diferenciado à primeira sentença, que apresentaria padrões distintos de tempo de processamento e recuperação (KINTSCH, 1974).

Tais assunções foram investigadas por Kieras (1978) em um estudo experimental sobre os efeitos da estrutura do parágrafo sobre o processamento de textos. Em seu trabalho, Kieras explorou justamente a hipótese de que os leitores usam a estruturação textual subjacente como estratégia para o reconhecimento de informações e consequente 
compreensão do texto. Ele propôs que os parágrafos (tomados como unidade de análise) são construídos de acordo com duas convenções acerca de sua forma estrutural. A primeira dessas convenções foi por ele denominada regra de topicalização inicial, a qual requer que o parágrafo se inicie com uma afirmação geral sobre o tema abordado. A segunda ele nomeou regra de coerência, por meio da qual cada sentença em uma sequência deva estar conectada a algo já anteriormente apresentado no parágrafo. Por meio de condições experimentais nas quais essas regras foram manipuladas de modo a produzirem textos em que elas eram violadas em maior ou menor grau, Kieras verificou o custo de processamento e o nível de entendimento dos leitores em tarefas de leitura e compreensão. Os resultados obtidos evidenciaram que os leitores percebem o modo de estruturação do texto, apresentando custos procedimentais menores e maior compreensão quando os textos respeitavam a topicalização inicial e a regra de coerência. Dessa forma, pode-se assumir que um parágrafo que apresente uma ideia principal logo em sua primeira sentença, com as demais se ligando a ela tematicamente, formando uma estrutura proposicional coerente, terá seu processamento e compreensão facilitados desde que os leitores sejam capazes de (a) identificar essa sentença principal e extrair informações dela e (b) conectar as demais sentenças que vão sendo lidas a essa sentença inicial, de modo a constituir mentalmente a unidade temática-formal do texto. É justamente essa possibilidade que será investigada no presente trabalho.

\section{0 papel das diferenças individuais}

Não obstante a importância da estruturação texto/parágrafo, na forma como aludido acima, é preciso considerar também a influência das diferenças individuais na leitura. Isso significa assumir a hipótese de que a estrutura do texto será reconhecida de forma diferente por diferentes leitores, com o custo de processamento e grau de compreensão variando conforme os distintos perfis de leitores, definidos em termos das capacidades e habilidades requeridas para uma adequada consecução da atividade de leitura de textos.

Long, Johns e Morris (2006) buscaram caracterizar as habilidades que definem leitores maduros, no que tange às suas capacidades de compreensão do texto. Os autores em questão definiram essas habilidades como sendo a) habilidades no nível da palavra, concernente a medidas como consciência fonológica e conhecimento explícito sobre a relação som-letra, b) diferenças no âmbito da memória de trabalho, assumida como um construto subjacente às tarefas de leitura, tomado como fundamental para uma boa execução leitora, c) habilidades de supressão (suppression abilities), também chamadas de inibição cognitiva, que são relativas à capacidade de os leitores ativarem apenas as informações que são relevantes para a devida compreensão do texto inibindo as que trazem dados irrelevantes para esse processo, permitindo assim a construção de uma representação textual coerente, d) capacidades relativas à prática leitora, dentro do que eles denominaram print exposure, e que dizem respeito ao grau de interesse e dedicação à leitura, e e) conhecimento prévio, definido como o conhecimento que fornece background para a adequada interpretação do conteúdo temático do texto. Dentro desse quadro, bons leitores seriam os que apresentam maiores escores em cada uma dessas habilidades, com a combinação entre elas potencializando as competências leitoras individuais.

Essas habilidades descritas por Long, Johns e Morris (2006) são concernentes a capacidades mais gerais, não se aplicando diretamente ao nível do reconhecimento de informações tópicas de um texto. Já o estudo de Maia (2018) segue na direção oposta, investigando a identificação das informações presentes em períodos compostos por diferentes tipos de leitores. Tomando por hipótese que a oração principal em um período contém a informação básica a qual as demais se subordinam, Maia verificou, por meio da técnica experimental do rastreamento ocular (eye-tracker) se os leitores em graus distintos de proficiência reconheciam essa oração quando sua posição no período era modificada. Os resultados 
mostraram que leitores proficientes identificam essa oração principal qualquer que seja a sua posição, e gastam mais tempo em sua leitura, de modo a extrair mais informações que serão tomadas como fundamentais para a correta compreensão do texto. Ainda que aplicada ao nível do período, a investigação de Maia (2018) pode ser estendida igualmente ao nível do parágrafo, assumindo que o tópico frasal inicial demandará maior custo de processamento, uma vez reconhecido pelos leitores, com a capacidade de reconhecê-lo e processá-lo definindo distintos perfis leitores.

A caracterização de perfis leitores em atividades de leitura de textos foi também explorada por Hyönä, Lorch Jr e Kaakinen (2002), desta vez já no nível do texto, numa abordagem mais estendida do que a que foi conduzida por Maia (2018). Os autores em tela conduziram um estudo com rastreamento ocular com vistas à caracterização de perfis leitores em atividades de leitura de textos não- manipulados. Numa análise estatística multivariada de agrupamentos (cluster analysis), na qual levaram em conta diversas medidas obtidas com eye-tracker (tais como número de fixações, tempo de fixação, número de movimentos de retorno ocular - backward movements), dentre outros, Hyönä et al. (2002) lograram agrupar os sujeitos participantes em quatro grandes categorias: a) leitores lineares rápidos (fast linear readers), que se caracterizaram por apresentar baixo número de retornos à informação anterior;' b) leitores lineares lentos (slow linear readers), que se caracterizaram pelo padrão oposto, isto é, pelo alto número de retornos à informação anterior; c) leitores não-seletivos (non-selective reviewers), definidos como sendo os que retornam sempre à sentença anterior, mesmo quando esta não apresenta informação relevante; e d) leitores de estruturas de tópico (topic structure processors), que são os que dão mais atenção aos núcleos de informação (headings). Essa caracterização leva em conta, portanto, as diferentes estratégias aplicadas pelos leitores em tarefas de leitura e compreensão, demonstrando que as diferenças individuais têm um peso no modo como um texto é processado.
Tomadas em conjunto, as propostas de Long, Johns e Morris (2006), Hyönä, Lorch Jr e Kaakinen (2002) e de Maia (2018) são indicativas de que é possível investigar 0 processamento textual assumindo-se que as diferenças individuais atuarão de algum modo, seja no nível da sentença, seja no nível do parágrafo ou do texto. Isso, combinado com a investigação sobre a maneira como a estrutura do texto interfere em seu processamento e compreensão, conduz a um entendimento mais estendido sobre os fatores que influem no processamento de textos em nível mental-cognitivo. Por essa razão, o estudo aqui conduzido assume como objetivos justamente avaliar o papel da estruturação do texto na compreensão leitora, identificando diferentes perfis leitores e como eles reagem diante da (boa/má) estruturação do texto. Além disso, visa também reconhecer as estratégias usadas pelos leitores durante a leitura, com vistas à sua percepção da estrutura do texto. A construção metodológica do estudo aqui apresentado será descrita na seção a seguir.

\section{Procedimentos metodológicos}

Para a investigação experimental conduzida aqui, foram criados textos que reproduziam a estrutura de um parágrafo que respeita a regra da topicalização inicial e a regra da coerência propostas por Kieras (1978). Os textos apresentavam um tópico frasal que expressava a ideia central a ser desenvolvida no parágrafo. Esse tópico frasal continha quatro substantivos (N1, N2, N3 e N4), os quais eram retomados nas demais frases do texto, criando assim uma coesão por repetição, assumindo-se, conforme Surber (2001), que a repetição de palavras pode atuar como recurso de coesão textual. O tópico frasal de cada texto seguia sempre a estrutura N1 (sujeito) + verbo $+\mathrm{N} 2$ (objeto) $+\mathrm{N} 3$ (adjunto) $+\mathrm{N} 4$ (adjunto). A distribuição de N1, N2, N3 e N4 pelas demais frases foi feita de modo a criar uma estrutura proposicional, seguindo o mesmo procedimento realizado por Kieras (1978) em seus experimentos. O esquema a seguir ilustra essa estrutura 
Figura 1 - Estrutura Proporcional

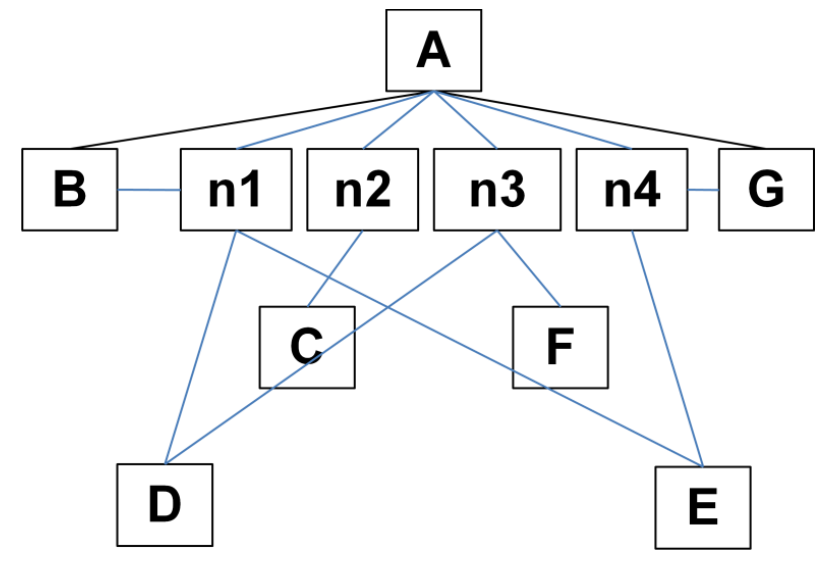

" $A$ ", no esquema acima, representa o tópico frasal, o qual abarca N1, N2, N3 e N4, que são retomados conforme as linhas que ligam os blocos. $\mathrm{N} 1$ é retomado nas sentenças "B", "D" e "E", N2 é retomado nas sentenças "C", "E" e "F", e assim sucessivamente. Cada $\mathrm{N}$ é, portanto, retomado três vezes ao longo do parágrafo. A única sentença que contém os quatro N's é o tópico frasal, dessa forma fazendo com que ele apresente não somente a ideia central do texto, mas também as informações novas (dadas), que serão retomadas na sequência. As demais sentenças retomam esses N's, sempre acrescentando uma informação secundária a eles.

A disposição das sentenças no texto obedeceu a uma ordenação que refletia as direções possíveis que os leitores poderiam seguir ao ler o texto. Tal ordenação foi seguida por Kieras (1978) e consistia em fazer com que o leitor ou começasse com o tópico frasal, ao qual iriam sendo conectadas as demais sentenças conforme se avançasse a leitura, dentro do que Kieras denominou leitura top-down, ou deixasse 0 tópico frasal por último, o que obrigaria o leitor a formar a unidade textual somente ao final da leitura, o que foi chamado por Kieras leitura bottom-up. Além disso, a ordenação igualmente contemplava a possibilidade de a direção seguir um movimento lateral, esgotando as sentenças em um lado do esquema antes de iniciar a leitura das sentenças no outro lado. Ou seja, o leitor, após ler o tópico frasal, poderia seguir a sequência " $B$ ", "C", "D", e depois a sequência "G", "F" e "E" Ou então poderia alternar sentenças em cada lado do esquema, seguindo a sequência "A", "B", "G", "C", "F", "D" e "E".
À primeira ordem Kieras denominou depth-first, e à segunda, breadth-first. Esses modos de ordenação se constituíram nas variáveis independentes do experimento, de cuja combinação em design fatorial resultaram as quarto condições experimentais aqui utilizadas: top-down/depth-first (TDDF), topdown/breadth-first (TDBF), bottom- up/depth-first (BUDF) e bottom-up/breadth-first (BUBF). O esquema a seguir ilustra essas combinações:

Figura 2 - Disposição das Sentenças no Texto

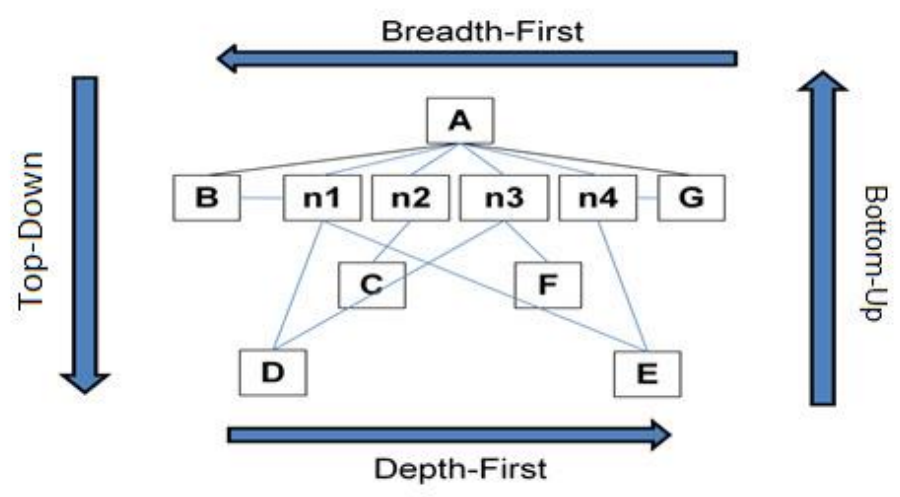


Abaixo seguem exemplos dos textos usados, cada um deles seguido uma condição experimental:

\begin{tabular}{|c|c|}
\hline $\begin{array}{l}\text { Condição TDDF } \\
\text { A. O presidente assinou a lei dos direitos dos trabalhadores. } \\
\text { B. O presidente ficou contente com a repercussão. } \\
\text { C. A lei entrará em vigor no próximo ano. } \\
\text { D. O presidente discutiu os direitos com os deputados. } \\
\text { G. Os trabalhadores comemoraram em todo o país } \\
\text { E. Os direitos são muito numerosos. } \\
\text { F. A lei favoreceu bastante aos trabalhadores. }\end{array}$ & $\begin{array}{l}\text { Condição TDBF } \\
\text { A. O presidente assinou a lei dos direitos dos trabalhadores. } \\
\text { B. O presidente ficou contente com a repercussão. } \\
\text { G. Os trabalhadores comemoraram em todo o país } \\
\text { C. A lei entrará em vigor no próximo ano. } \\
\text { F. A lei favoreceu bastante aos trabalhadores. } \\
\text { D. O presidente discutiu os direitos com os deputados. } \\
\text { E. Os direitos são muito numerosos. }\end{array}$ \\
\hline 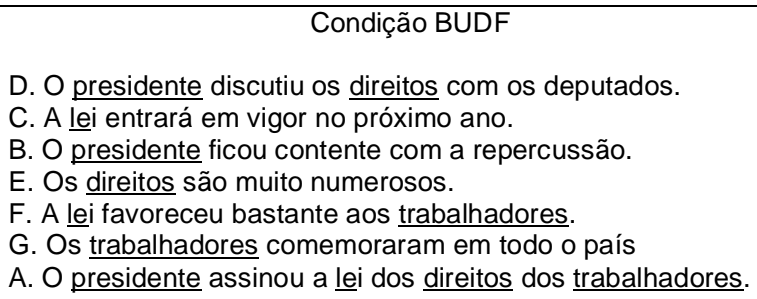 & $\begin{array}{l}\text { Condição BUBF } \\
\text { D. O presidente discutiu os direitos com os deputados. } \\
\text { E. Os direitos são muito numerosos. } \\
\text { C. A lei entrará em vigor no próximo ano. } \\
\text { F. A lei favoreceu bastante aos trabalhadores. } \\
\text { B. O presidente ficou contente com a repercussão. } \\
\text { G. Os trabalhadores comemoraram em todo o país } \\
\text { A. O presidente assinou a lei dos direitos dos trabalhadores. }\end{array}$ \\
\hline
\end{tabular}

Assumiu-se que as previsões acerca do processamento e compreensão das dos textos acima seriam as mesmas estabelecidas por Kieras (1978), ou seja, na medida em que a topicalização inicial é uma estruturação que facilita a leitura do texto, esperava-se os desempenho melhor dos sujeitos nas condições top-down, em face às bottom-up. Além disso, a regra de coerência é mais atinente com a direção em sequência direta, mais do que em sequência alternada, de onde se pode prever um melhor desempenho nas condições depth-first, em comparação com as breadthfirst. Tais previsões são exploradas em mais detalhes a seguir.

\subsection{Sujeitos}

21 estudantes de graduação e pós-graduação da UFPB, com idades entre 22 e 35 anos, sendo 10 do sexo feminino e 11 do sexo masculino

\subsection{Materiais}

4 listas de textos, cada qual com 16 textos, 4 em cada condição experimental, em um design em

\footnotetext{
1 O Índice de Facilidade de Leitura de Flesch é uma medida que informa o grau de dificuldade de compreensão durante a leitura de uma passagem. Ele usa um conjunto de medidas (comprimento da palavra e da sentença, número de palavras,
}

quadrado latino (latin square design), totalizando então 64 textos. Cada texto continha 7 frases cada, controladas por tamanho em letras (301 a 314 letras, com média 305,5), sílabas (114 a 121, com média 105,3), palavras (50 a 53, com média 50,9), e Índice de Facilidade de Leitura de Flesch ${ }^{11}$ entre 80 e 90 . Os tópicos frasais de cada texto também foram controlados, apresentando tamanho entre 50 e 59 letras (média de 52,8), sílabas (entre 18 e 21, com média 19,9), palavras (sempre em número de 9), e Índice de Facilidade de Leitura de Flesch, mais uma vez, acima de 80 pontos.

\subsection{Aparato}

O experimento foi montado e aplicado utilizando-se o software Paradigm, que é projetado para a apresentação de estímulos e registro de dados. Este software foi instalado em um computador desktop HP Intel I5, instalado nas dependências do Laboratório de Processamento Linguístico (LAPROL) da Universidade Federal da Paraíba. O local possui iluminação adequada, móveis apropriados para garantir o conforto dos sujeitos durante a tarefa

sílabas e letras) e pode ser interpretado utilizando uma escala de 0 a 100), sendo que o texto padrão é aquele situado entre 60 e 70 . 
experimental e é livre de ruídos e interferências externas.

\subsection{Procedimento}

As frases dos textos experimentais foram apresentadas uma a uma. A cada frase lida, os sujeitos apertavam uma tecla pré-definida, registrando-se então o tempo de leitura da frase e passando-se à frase seguinte, até a frase final, quando era também registrado o tempo total de leitura. Ao final de cada texto, era requerido dos sujeitos que escrevessem, em um espaço limitado, um resumo do texto recém lido. Esse resumo foi posteriormente avaliado, registrandose o escore máximo de 4 sempre que os 4 substantivos referentes a N1, N2, N3 e N4 fossem retomados no resumo, com escore minímo de 0 (zero) quando nenhum dos $\mathrm{N}$ era retomado no resumo. Tal medida foi escolhida para garantir uma certa objetividade da avaliação do resumo, igualmente permitindo que se aferisse o grau de atenção e retenção dessa informação, tomada como fundamental à compreensão do texto, por parte dos sujeitos. Houve uma sessão prévia de treinamento, para que os sujeitos se habituassem à tarefa experimental.

Tomaram-se como variáveis dependentes, portanto, o tempo de leitura do tópico frasal, o tempo de leitura total do texto e o escore obtido no resumo. As hipóteses assumidas foram as de que a topicalização inicial é fundamental para a boa estruturação do parágrafo, pois é a partir dela que se organizam as demais informações do texto, daí se prevendo menores tempos de leitura total do texto nas condições top-down, comparativamente às condições bottom-up. A segunda hipótese é que os sujeitos buscam o tópico frasal nos parágrafos durante a leitura, assumindo que a primeira frase sempre corresponde ao tópico do parágrafo, com a previsão de que menores tempos de leitura do tópico frasal nas condições top-down, comparativamente às condições bottom-up seriam registrados. Por fim, assumiu-se também a hipótese de que textos em que as informações se articulam adequadamente em torno do tópico frasal têm sua compreensão facilitada, com maiores escores do resumo nas condições top-down, comparativamente às condições bottom-up sendo registrados.

\subsection{Resultados e Discussões}

Os resultados obtidos foram submetidos a uma análise de regressão linear simples, em dois modelos distintos, com as condições experimentais servindo como variável explicativa nos dois modelos, e o tempo de leitura total e o tempo de leitura do tópico frasal servindo como variáveis de resposta, cada uma em um modelo. O gráfico a seguir mostra os resultados da análise do primeiro modelo: 


\section{Gráfico 1}

\section{Tempo de Leitura Total}
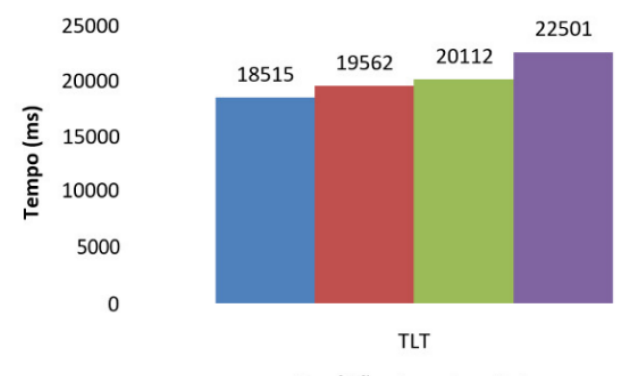

Condições Experimentais

Não se registraram diferenças significativas entre os tempos de leitura total nas condições experimentais $(F(3,60)=1,04, p>0.05)$, não se confirmando assim a primeira das hipóteses assumidas aqui. A topicalização inicial pareceu não interferir no custo de processamento on line do texto, ainda que se tenha verificado uma tendência nesse sentido, ao se observar um tempo total de leitura crescente. Uma medida de tamanho de efeito (effect size) mostrou um efeito moderado ( $d$ de Cohen $=0.38$, com $r=-0.19$ ) entre as condições top-down e bottomup, sugerindo que essa última acarreta um efeito sobre o tempo de leitura, efeito esse um tanto tímido quando se considera o processamento reflexo do texto, na direção da tendência observada. Contudo, a confirmação dessa tendência requereria um aumento no tamanho da amostra empregada aqui, testando-se um número maior de sujeitos. É possível sugerir, diante desses dados, que os leitores tomam a primeira sentença como sendo o tópico frasal, fazendo uma leitura que associa as demais frases a ele em algum grau, mas só percebendo a má estruturação em etapas posteriores do processo de compreensão o texto.

No que se refere à variável tempo de leitura do tópico frasal, os resultados da análise do segundo modelo são mostrados no gráfico a seguir:

\section{Gráfico 2}

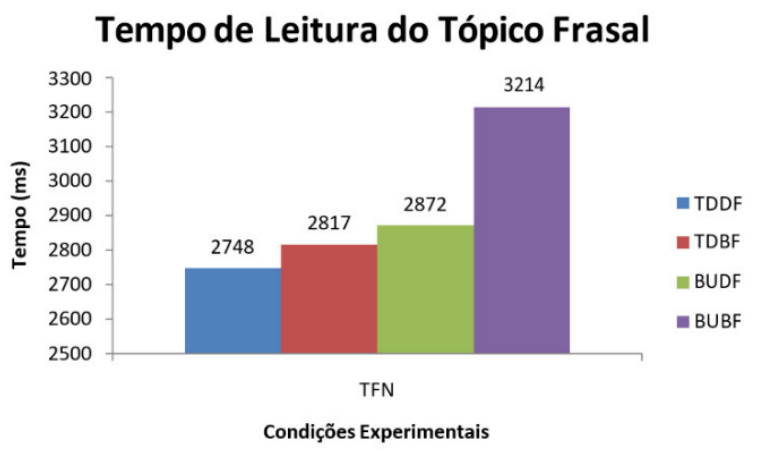

Diferenças significativas entre os tempos de leitura do tópico frasal nas condições experimentais foram verificadas $(F(1,59)=6,45, \quad p<0.05)$, confirmando assim a segunda das hipóteses assumidas aqui. A diferença pareceu emergir da comparação entre as condições TDDF, TDBF, BUDF com a condição BUBF, que apresentou um tempo de leitura significativamente distinto das demais. Aqui, a topicalização inicial pareceu interferir no custo de processamento on line do texto desta vez, já que se pode sugerir que o aumento no tempo de leitura se deve ao fato de o tópico frasal estar na última posição - para que ocorresse uma integralização adequada das informações textuais, seria necessário que os leitores reconhecessem esse elemento integrador, que seria, no caso, o tópico frasal. Uma vez identificado na primeira posição, essa atividade de integração pode ocorrer ao longo da leitura, ao passo que, estando na última posição, isso só ocorreria quando do término da leitura, fazendo com que o leitor se demorasse mais na leitura do tópico frasal. Assim, a segunda hipótese aqui proposta fica evidenciada, com os leitores buscando o tópico frasal como estratégia para a compreensão do texto.

Uma análise de correlação entre os tempos de leitura total e os tempos de leitura do tópico frasal também foi realizada (Teste de Correlação de Pearson) com vistas a prover mais algumas evidências empíricas sobre a topicalização inicial e seu uso como estratégia de leitura. $O$ resultado aparece no gráfico a seguir: 
Gráfico 3 - Correlação entre Tempos de Leitura

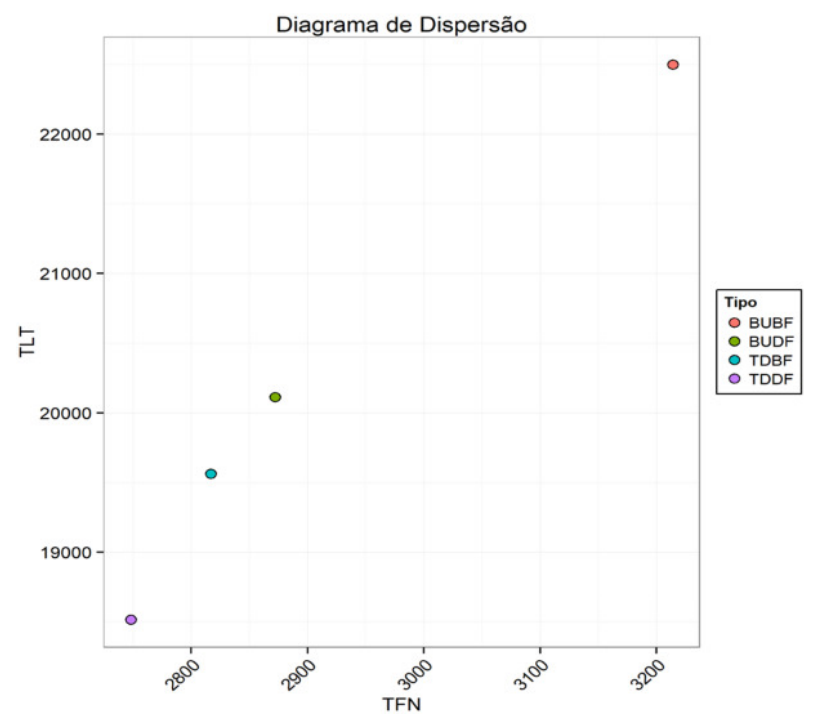

É possível verificar no Gráfico 3 uma correlação positiva $(r=0.98$ e $p<0.05)$ entre o tempo de leitura total (eixo y) e o tempo de leitura do tópico frasal (eixo $x)$. As condições experimentais TDDF e TDBF requerem menores tempos de leitura do tópico, o que acarreta menores tempos de leitura total, devido ao fato de o reconhecimento do tópico já na primeira posição facilitar a integralização das informações. Já as condições BUDF e BUBF requerem tempos maiores de leitura do tópico frasal, acarretando um tempo maior de leitura total, uma vez que as informações necessitam ser integralizadas somente quando do reconhecimento do tópico. A melhor estratégia, portanto, parece ser a de buscar o tópico frasal para, a partir dele, empreender a tarefa de conexão entre as sentenças do texto, no que se refere ao seu conteúdo temático.

No que se refere aos escores do resumo, os resultados são apresentados no gráfico a seguir:

\section{Gráfico 4}

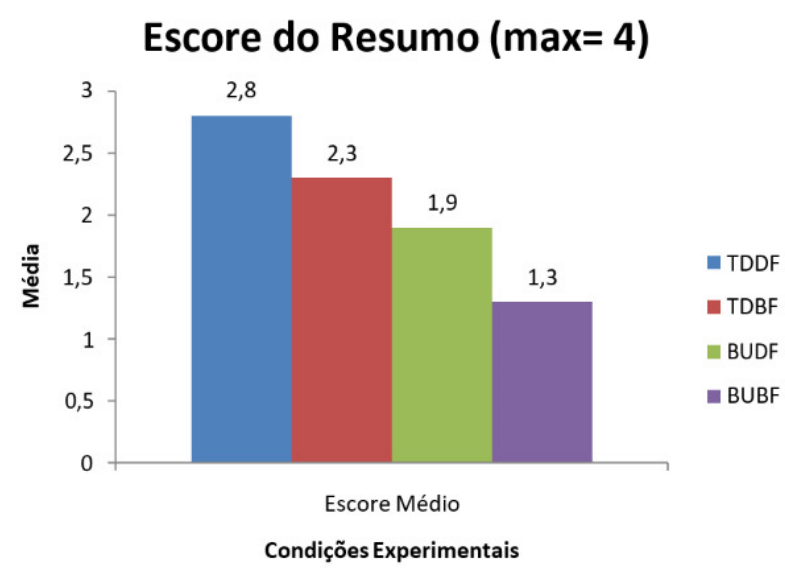

Os resultados dos escores parecem indicar que a compreensão mais adequada do texto ocorre nas condições TDDF e TDBF, comparativamente às condições BUDF e BUBF, conforme o previsto pela terceira hipótese aqui assumida. Tal resultado vai de encontro à assunção aqui feita, de que os textos em que as informações são articuladas adequadamente em torno do tópico frasal tem sua compreensão facilitada. No entanto, é preciso frisar que o escore mede apenas a percepção das informações contidas no tópico frasal e o quanto essas informações são articuladas com as demais no texto, não se constituindo em uma medida mais completa acerca da compreensão global do texto, o que só poderia ter sido feito com uma avaliação mais pormenorizada dos resumos produzidos pelos sujeitos, o que se prevê em uma etapa posterior do estudo aqui conduzido.

Por fim, os resultados foram submetidos a uma análise de agrupamentos (cluster analysis), método hierárquico, com o objetivo de identificar diferentes perfis leitores, conforme a estratégia por eles utilizada. A análise levou em conta os resultados obtidos pelos sujeitos nas três variáveis dependentes aqui consideradas, de acordo com as condições experimentais. Duas análises distintas foram empreendidas: uma, que agrupou as respostas em função das condições experimentais, e outra, que efetivou o agrupamento levando em conta apenas os sujeitos participantes. Os resultados da primeira análise aparecem no gráfico a seguir: 
Gráfico 5 - Análise de Cluster (I)

Agrupamento: Método Hierárquico

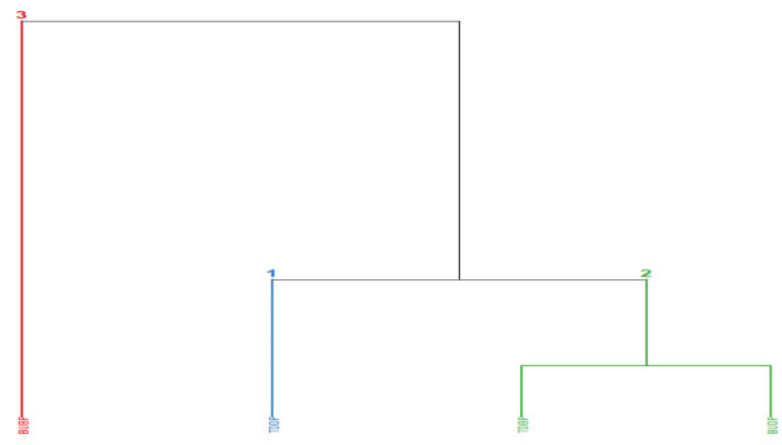

O que o Gráfico 5 ilustra é que as condições apresentam três características distintas, cada qual correspondendo a um agrupamento próprio. No primeiro agrupamento, temos a condição BUBF, que se caracteriza por apresentar escores baixos no que se refere ao resumo, bem como tempo de leitura total e tempo de leitura do tópico frasal elevados. Isso sugere que essa condição induz tanto dificuldades na compreensão quanto no processamento, comparativamente às demais condições. Já a condição TDDF tem comportamento distinto: ela parece elicitar uma maior compreensão por parte dos leitores, ao mesmo tempo em que o seu custo de processamento decai, visto os escores serem maiores e os tempos de leitura total e do tópico serem menores. O dado interessante é que elas correspondem a tipos diametralmente opostos, com a condição TDDF situando-se em um extremo, que corresponde ao ponto em que compreensão e processamento estão em nível ótimo, ao passo que a condição BUBF localiza-se no extremo oposto, justamente no ponto em que compreensão e processamento estão em nível péssimo. Assim, a elaboração de textos que sigam a regra da topicalização inicial, tanto quanto uma regra de coerência baseada em uma sequência depth-first conduz a uma estratégia de leitura que garante melhores resultados, face às demais formas de estruturação textual. $\mathrm{O}$ fato de as condições TDBF e BUDF serem agrupadas na mesma categoria reforça esse entendimento, na medida em que correspondem a alterações que logram modificar o grau de compreensão do texto, bem como o nível de dificuldade de processamento.
Já a segunda análise tem os seus resultados ilustrados no gráfico a seguir:

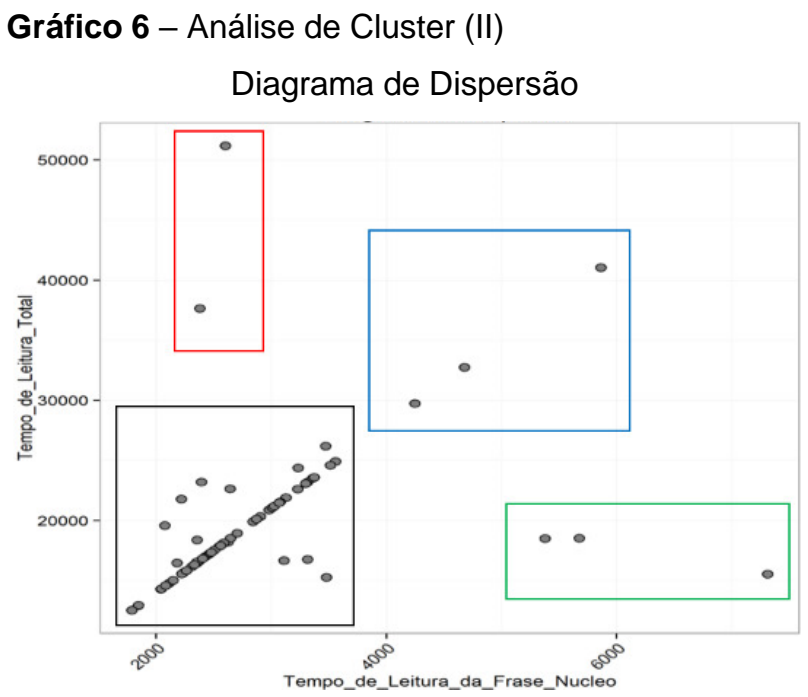

A análise ilustrada do Gráfico 6 permite a identificação de quatro grupos de leitores. O primeiro deles, correspondente ao quadrado de cor preta no gráfico acima, representa os leitores que leram o tópico frasal em tempo relativamente curto, economizando assim o tempo total de leitura, que também permaneceu baixo. Esse perfil parece definir uma estratégia que se baseia em consumir o mínimo de recursos possível, em detrimento até de boa compreensão do texto - nesse sentido, se assemelham aos fast linears readers de Hyönä et. al. (2002) - e sendo a estratégia preferencial da maioria dos leitores. Depois, pode-se apontar os que seguiram na mesma tendência, mas não sacrificando a compreensão: são os que correspondem ao quadrado em azul acima, que tiveram o tempo de leitura total subindo na mesma proporção que o tempo de leitura do tópico frasal, mas com uma maior atenção ao conteúdo do texto. Em terceiro, os que preferiram gastar tempo na leitura do tópico frasal, para economizar no tempo de leitura total: são os indicados no quadrado de cor verde. Por fim, tem-se os que foram lentos tanto na leitura do tópico frasal quanto no tempo de leitura total, indicados em vermelho - esses se assemelham aos slow linear readers de Hyönä et. al. (2002) na medida em que leem o texto de forma sequencial e demorada em cada uma das partes. Esses diferentes perfis sugerem que, em realidade, os 
leitores lançam mão, na maioria das vezes, de uma estratégia que não se configura exatamente como tal: é uma leitura linear, não hierarquizada, que não busca distinguir as partes de um texto, muito menos articulálas - um comportamento que parece condizer com a situação atual da leitura em nosso país, frequentemente mal avaliada por métricas reconhecidas de aferição de competência leitora, o que parece sugerir a necessidade de intervenção.

\section{Considerações finais}

De um modo geral, pode-se dizer que 0 experimento aqui conduzido proveu evidências em favor das hipóteses assumidas, em que pese o seu caráter exploratório. A organização do parágrafo revelou-se como um fator importante na compreensão do texto, uma vez assumido o parágrafo como uma unidade textual. A topicalização inicial pareceu ser uma estratégia adequada de formulação do texto e, uma vez que é deixada clara no parágrafo, permite ao leitor o seu reconhecimento e depreensão, facilitando assim a integralização das informações e consequente incremento na compreensão textual. Por outro lado, os leitores não pareceram comportar-se de modo igual diante de textos bem ou mal estruturados: diferentes perfis leitores reagiram de modos distintos diante da tarefa de ler e compreender textos, o que aponta para um estudo mais pormenorizado das características dos bons leitores e suas capacidades subjacentes, algo que escapa ao escopo do presente trabalho.

Como follow up, a pesquisa aqui esboçada pretende continuar a aplicação do experimento, de forma a ampliar a amostra pesquisada, a fim de poder evidenciar de modo mais categórico as tendências aqui apenas captadas e, daí, prover dados mais robustos sobre o papel da estrutura do parágrafo na compreensão leitora. Um outro ponto a ser investigado nesse tema é o da função dos conectivos no processo de conexão entre sentenças e a integralização das informações - daí que um passo seguinte será o de montar uma versão dos textos experimentais, usando elementos conectivos, de forma a poder avaliar o papel desses elementos no processamento e na compreensão do texto. Diferenças quanto à escolaridade também necessitam ser exploradas, razão pela qual se pretende aplicar as duas versões do experimento em sujeitos com diferentes níveis de escolaridade. Por fim, o estudo aqui iniciado pretende utilizar a metodologia de rastreamento ocular (eyetracker) de forma a se obter medidas on-line de processamento do texto.

Os resultados aqui obtidos de forma alguma podem ser tomados como definitivos, mas parecem apontar para tendências que, devidamente exploradas, proverão subsídios que poderão embasar um maior entendimento do modo como textos são produzidos e compreendidos, o que poderá, no futuro, promover um incremento pedagógico no ensino de língua materna e produção de textos escritos, algo que urge diante do precário quadro de desenvolvimento educacional do nosso país. Dentro de uma nova perspectiva da Psicolinguística Experimental moderna, que se alia a disciplinas igualmente voltadas para a educação e seu desenvolvimento, como a Psicologia Cognitiva e Neurociências, o trabalho aqui apresentado vem dar a sua modesta contribuição. $O$ seu desenvolvimento subsequente deverá seguir as mesmas diretrizes, enquanto puder realmente atuar no progresso das ciências da linguagem, de um lado, e na melhoria da formação cognitiva e intelectual de nossos alunos.

\section{Referências}

BUDD, Desiree; WHITNEY, Paul; TURLEY, Kandi J. Individual Differences in Working Memory Strategies for Reading Expository Text. Memory and Cognition, 23, 735-748, 1995

HYÖNÄ, Jukka; LORCH Jr. Robert; KAAKINEN, Johanna K. Individual Differences in Reading to Summarize Expository Text: Evidence From Eye Fixation Patterns. Journal of Educational Psychology, 94, 44-55, 2002

KIERAS, David. Good and Bad Structure in Simple Paragraphs. Effects on Apparent Theme, Reading Times and Recall. Journal of Verbal Learning Behavior, 17, 13-28, 1978. 
KINTSCH, Walter; RAWSON, Katherine A. Compreensão . In: SNOWLING, Margaret J; HULME, Charles. A. A Ciência da Leitura. Porto Alegre: Penso, 2013.

KINTSCH, Walter; VAN DIJK, Teun. Toward a Model of Text Comprehension and Production. Psychological Review, 85, 5, 363-391, 1978.

LONG, Debra L.; JOHNS, Clinton L.; MORRIS, Phillip E. Compreehension Ability in Mature Readers. In: TRAXLER, Matthew; GERNSBACHER, Morton A. Handbook of Psycholinguistics. Cambridge: CUP, 2006

MAIA, Marcus. Computação Estrutural e de Conjunto na Leitura de Períodos: Um Estudo de Rastreamento Ocular. In: MAIA, Marcus (org.) Psicolinguística e Educação. Campinas: Mercado das Letras, 2018.

SURBER, John R. Effect of Topic Label Repetition and Importance on Reading Time and Recall of Text. Journal of Educational Psychology, 93, 279-287, 2001.

\section{COMO CITAR ESSE ARTIGO}

NETO, José Ferrari. A estrutura do parágrafo na compreensão leitora: um estudo exploratório. Signo, Santa Cruz do Sul, v. 45, n. 82, jan. 2020. ISSN 1982-2014. Disponível em: <https://online.unisc.br/seer/index.php/signo/article/view/14349>. . doi:https://doi.org/10.17058/signo.v45i82.14349. em: 